\title{
PERFIL SÓCIO ECONÔMICO E CULTURAL DOS INGRESSANTES NO CURSO DE AGRONOMIA DO CENTRO UNIVERSITÁRIO FAG - CASCAVEL- PARANÁ
}

\author{
Ana Paula Morais Mourão Simonetti ${ }^{1}$, Caroline Beal Montiel $^{2}$, Guilherme Mascarello ${ }^{3}$ \\ ${ }^{1}$ Engenheira Agrônoma. Doutoranda em Engenharia Agrícola (UNIOESTE), \\ Cascavel, Brasil \\ ${ }^{2}$ Engenheira Agrônoma, Centro Universitário da Fundação Assis Gurgacz (FAG), \\ Cascavel, Brasil (caroline_montiel@hotmail.com) \\ ${ }^{3}$ Engenheiro Agrônomo, Centro Universitário da Fundação Assis Gurgacz (FAG), \\ Cascavel, Brasil
}

Recebido em: 03/10/2016 - Aprovado em: 21/11/2016 - Publicado em: 05/12/2016 DOI: 10.18677/EnciBio_2016B 075

$\begin{array}{cl}\text { RESUMO } & \\ \text { Objetivou-se avaliar o perfil dos acadêmicos que ingressaram no curso de }\end{array}$ Agronomia do Centro Universitário Assis Gurgacz, Cascavel-PR, no ano de 2016. Justifica-se esse estudo para disponibilizar melhorias no curso de acordo com suas necessidades estudantis e conhecimento do perfil dos acadêmicos. A pesquisa foi de maneira exploratória quantitativa, participando da amostra 83 alunos. A coleta de dados se deu por meio de um questionário com perguntas fechadas, onde se verificou que: existe uma predominância do gênero masculino com idade entre 16-18 anos. O principal meio de transporte utilizado pelos acadêmicos é o ônibus sendo que a maior parte vem de outras cidades. Além disso, é possível destacar que $14 \%$ dos alunos possuem ensino médio técnico, e que grande parte dos alunos além de estudar trabalha, e quando questionados no que pretendem trabalhar após a graduação houve predominância na escolha de cooperativas e multinacionais. Mais da metade dos pais são produtores rurais e são também os principais responsáveis financeiros, sendo que a principal forma de pagamento utilizada é a mensal.Em relação ao principal motivo da escolha do curso, $76 \%$ dos alunos destacaram que possuem identificação com o curso. A atração de $52 \%$ dos entrevistados em cursar Agronomia na FAG foi devido à qualidade da estrutura.

PALAVRAS-CHAVE: Ensino superior, fator de escolha do curso, estudantes.

\section{SOCIOECONOMIC AND CULTURAL PROFILE OF THE ENTERING STUDENTS IN THE COURSE OF AGRONOMY FAG UNIVERSITY CENTER - CASCAVEL- PARANÁ}

\footnotetext{
ABSTRACT

The objective was to evaluate the profile of students who enrolled in the course of Agronomy of the University Center Assisi Gurgacz, Cascavel-PR, in the year 2016. It is justified this study to provide improvements in the course according to their student needs and profile of the knowledge of academics. The research was exploratory quantitative way, taking part in the sample 83 students. Data collection was done through a questionnaire with closed questions, where it was found that: there is a predominance of males aged 16-18 years. The main means of transport used by academics is the bus and that most of it comes from other cities. Moreover, it is ENCICLOPÉDIA BIOSFERA, Centro Científico Conhecer - Goiânia, v.13 n.24; p.803 2016
} 
possible to highlight that $14 \%$ of students have technical high school, and that many of the students besides studying works, and when asked what they intend to work after graduation predominated in choosing unions and multinationals. More than half of parents are farmers and are also the main financial officers, and the main form of payment used is the mensal.Em relation to the main reason for choosing the course, $76 \%$ of students have pointed out that identification with the course. Attracting $52 \%$ of respondents attend Agronomy in FAG was due to the quality of the structure.

KEY WORKS: Higher education, factor of choosing that course, students.

\section{INTRODUÇÃO}

Nos últimos anos ocorreu um crescimento acentuado de estudantes de nível superior no Brasil. Em 2015 o número de estudantes matriculados chegou a 8.033.574, representando 2,5\% de acrescimo em relação á 2014 (INEP, 2015). A participação do setor privado na educação superior teve maior crescimento em varios países, do que os investimentos do setor público, sendo estes investimentos são indicativos de que existe um espaço muito grande para o continuo crescimento da educação no país (SAMPAIO, 2011). Apesar disso ainda é baixa a taxa de escolarização da população brasileira entre 18-24 anos, que é de aproximadamente 14,4\% (INEP, 2010).

A educação pode ser entendida como forma de mudança na sociedade, possibilitando maior acesso ao mercado de trabalho, e assim contribuindo para diminuir os índices de pobreza e promover o crescimento socioeconômico do país (SICSÚ \& CASTELAR, 2009). Com isso, ao se conhecer as caracteristicas dos alunos o processo educacional torna-se eficiente, devido a esse conhecimento auxiliar na construção de metodologias educacionais que serão aplicadas (PAIVA, 2008).

Atualmente a juventude vive um dilema entre "ficar" ou "sair" do campo (CASTRO, 2005). Há uma tendência de migração de jovens do meio rural para o meio urbano, que normalmente está atrelado a busca por ensino superior nos grandes centros urbanos e aumento de renda (STROPASSOLAS, 2006). O ambiente rural, atualmente, não se caracteriza somente por atividades agrícolas, mas por um ambiente de muitos setores e atividades. Além disso, é um ambiente que se caracteriza pela baixa densidade populacional, mas não se encontra isolado dos meios urbanos (KAGEYAMA, 2003). Essa aproximação entre rural e urbano, além da perda de perspectivas, afeta a decisão dos jovens na definição de sua colocação na sociedade (CARNEIRO, 1998).

O curso de Agronomia é uma opção de curso de nível superior dentre os diversos cursos existentes no sistema educacional. $O$ discente que cursa essa formação recebe a titulação de Engenheiro Agrônomo, tendo conhecimentos desenvolvidos para sua área de atuação (BORGES, 2000). Os ingressos que já atuaram na área Agronômica, procuram a formação acadêmica, buscando agregar conhecimento teórico à experiência profissional, e os que ainda não atuaram na área buscam ter melhor oportunidade no mercado de trabalho (ARTUZO, 2012).

O ensino de Agronomia foi regulamentado no Brasil no ano de 1910, por meio do Decreto Presidencial no 8.319, de 20 de outubro de 1910. A primeira escola de Agronomia do país foi criada em 1875 na Bahia (CAPDEVILLE, 1991). A partir do dia 12 de outubro de 1933, o Agrônomo passou a receber a titulação de Engenheiro Agrônomo. Apesar disso, o curso continua sendo chamado de Agronomia por ser uma ciência, e não um ramo da Engenharia (ELIAS et al., 2003). 
O Engenheiro Agrônomo possui um amplo campo de atuação no mercado de trabalho, englobando áreas de produção agricola e animal, defesa fitossanitária, construções rurais, mecanização agrícola, agronegócio e planejamento rural (CASSOL, 2014). O Centro Universitário FAG, sediado em Cascavel, no oeste do Paraná foi fundada no ano de 1997. A instituição possui um histórico de prestação de serviços socioeducativos na comunidade, contribuindo assim em um dos setores mais importantes da sociedade. $\mathrm{O}$ curso de Agronomia iniciou as atividades no ano de 2004, e atualmente possui uma carga horária mínima de 4.000 horas, sendo que o curso é de período integral (mínimo de 4 anos) ou noturno (mínimo de 5 anos) (FAG, 2016).

Conhecer o perfil sócio-econômico dos acadêmicos de Agronomia é muito importante para o desenvolvimento de políticas de assistência estudantil, visando uma melhoria nos métodos de ensino para os alunos e a redução no ensino superior. Sendo que todos os órgãos educativos devem se colocar em disponibilidade para estabelecer estas melhorias (FERREIRA et al, 2015).

Diante do exposto, objetivou-se avaliar o perfil dos acadêmicos ingressos no curso de agronomia do Centro Universitário Assis Gurgacz, de Cascavel - PR, para disponibilizar melhorias no curso de acordo com suas necessidades estudantis, não somente para o centro, mas também para o perfil da Agronomia no país.

\section{MATERIAL E MÉTODOS}

Realizou-se a pesquisa no Centro Universitário Assis Gurgacz - FAG, localizado na cidade de Cascavel-PR no início do ano letivo de 2016, onde foram entrevistados 83 estudantes do primeiro ano do curso de Agronomia. A coleta de dados foi realizada pela aplicação de um questionário estruturado com perguntas fechadas, com alternativas variadas para cada questão.

Segundo GIL (1999) entrevista com perguntas fechadas é caracterizado como entrevista estruturada. Pela possibilidade de quantificar os dados, esse tipo de entrevista é adequado para levantamentos. Dentre as principais vantagens desse tipo de entrevista estão à rapidez de realização dos levantamentos e a possibilidade de realizar análise estatística dos dados, já que as respostas são padronizadas (BRITTO \& FERES, 2011).

Foram analisadas as seguintes questões: Idade e sexo dos estudantes, cidade onde reside, profissão dos pais, escolaridade dos ingressantes anterior ao ensino superior, trabalho atual, motivo pelo qual escolheram cursar Agronomia, área em que pretendem atuar após sua formação, qual a forma em que realizam o pagamento do curso e quem é seu responsável financeiro, qual o meio de transporte utilizado para chegar à faculdade e o que mais interessou aos ingressantes a cursar Agronomia no Centro Universitário- FAG. Os dados obtidos foram analisados por meio de estatística descritiva.

\section{RESULTADOS E DISCUSSÃO}

Após a análise dos dados, pode-se observar que 63\% dos alunos ingressantes possuem entre 16-18 anos, ou seja, os ingressantes do curso de Agronomia têm por característica continuar os estudos logo após a conclusão do ensino médio, tendo uma definição de qual formação querem seguir. Estes dados mostram relação à pesquisa realizada no ano de 2015 no Centro Universitário FAG por SIMONETTI et al. (2015), onde $72 \%$ dos alunos ingressantes tinham entre 17-20 anos. Em estudos realizados por RONCA \& RAMOS (2010), pode-se observar 
que houve um aumento de $6,9 \%$ para $13,9 \%$ de jovens cursando o ensino superior de 1998 a 2008.

Em relação à escolaridade dos ingressantes observou-se que $84 \%$ haviam concluído o ensino médio e $14 \%$ destes obtinham além do ensino médio regular a formação do ensino técnico, isso demonstra que além da base do ensino médio, alguns dos alunos procuram já se tornar técnico em alguma área, possibilitando uma visão mais ampla do ensino.

Também analisou-se a questão dos gêneros do alunos ingressantes, onde $80 \%$ dos alunos são do sexo masculino e $20 \%$ destes são do sexo feminino. Esse dado indica que ainda existe um número maior de homens interessados no curso de Agronomia, porém com um crescimento no interesse feminino de buscar esta formação. ARTUZO et al., (2012) verificaram que 65\% dos alunos entrevistados de Agronomia da UFSM (Universidade Federal de Santa Maria), são do sexo masculino e $35 \%$ do sexo feminino, nesse caso, indicando um expressivo número de ingressantes mulheres.

Analisando a distância entre a localidade dos ingressantes do curso de Agronomia até Cascavel-PR, conforme a Figura 1, pode-se destacar que apenas $25 \%$ dos alunos são de Cascavel, sendo $75 \%$ de outras localidades, sendo que $23 \%$ percorrem entre $50-100 \mathrm{~km}$ e $24 \%$ percorrem entre $100-150 \mathrm{~km}$, e existem acadêmicos até mesmo de outros estados. Esses resultados relacionam-se com a questão de qual meio de transporte é o mais utilizado para chegar até a faculdade, tendo o ônibus como o principal meio (63\%), demostrando que a maioria dos estudantes acaba vindo de outros municípios próximos e retornando à eles diariamente, ao final da aula.

Existe também uma relação com o turno de realização do curso, sendo que são abertas turmas integrais e noturnas. Foram entrevistados acadêmicos de ambos os turnos, e pode-se observar que grande parte dos estudantes de Cascavel opta pelo curso integral e os estudantes de outras localidades optam pelo curso noturno principalmente pela questão de transporte e por trabalhar durante o dia.

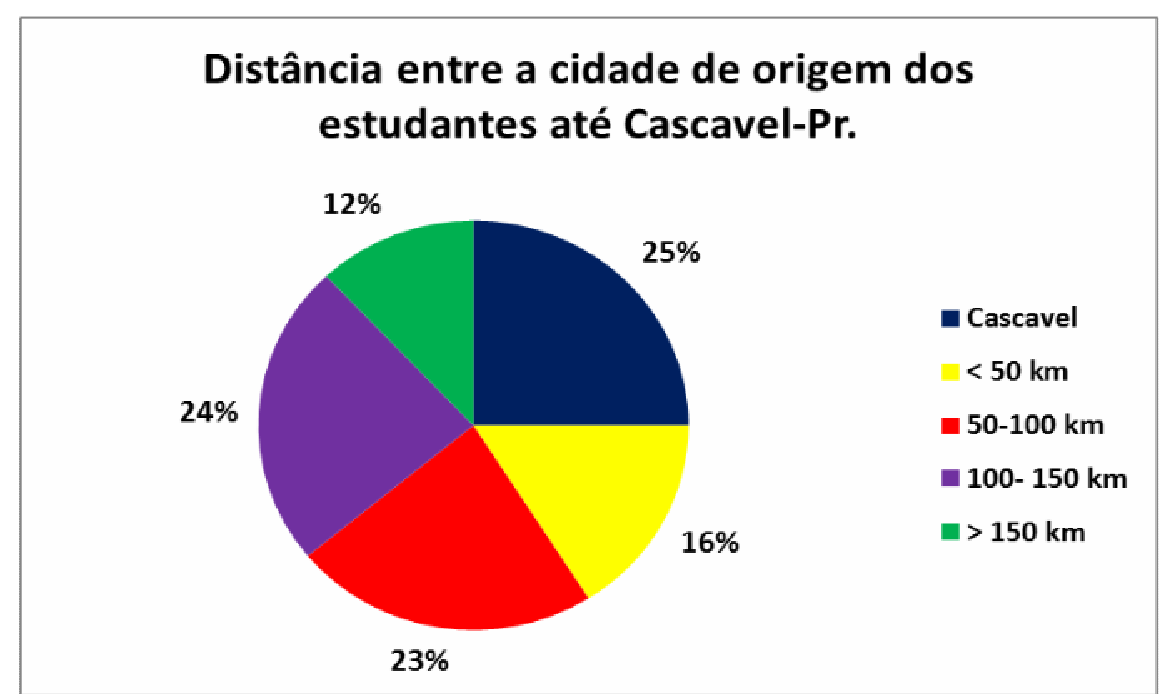

FIGURA 1 - Distância entre a cidade de origem dos estudantes do curso de Agronomia até Cascavel-PR.

O fato da maioria dos estudantes de Agronomia do Centro Universitário FAG não residirem em Cascavel, indica que a cidade tem sido vista como um polo estudantil, e que moradores das cidades vizinhas buscam nesse município sua qualificação e profissionalização. 
$\mathrm{Na}$ Figura 2, em relação à profissão dos pais dos alunos ingressantes, verifica-se que $51 \%$ dos pais relacionam-se com atividades rurais, fazendo com que os alunos tenham maior interesse na área, não só por continuar e manter o sustento da família, mas como forma de trazer melhorias e tecnologias para suas propriedades por meio de uma formação superior. Estes resultados também foram observados no trabalho de SIMONETTI et al., (2015), onde 53\% dos pais dos alunos de Agronomia entrevistados, eram produtores rurais.

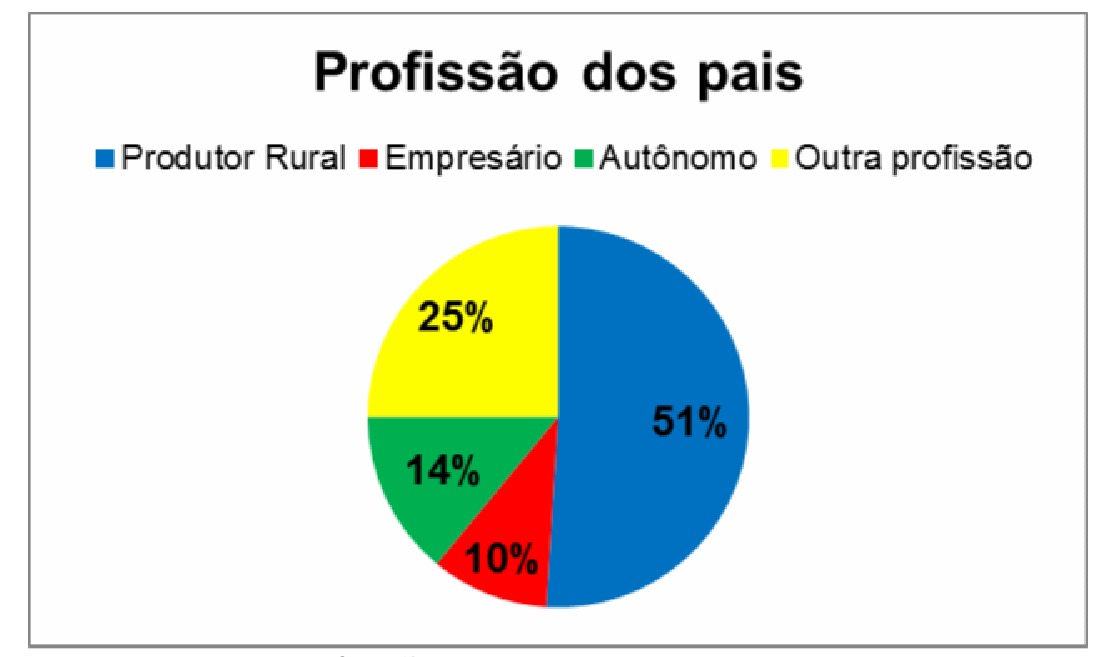

FIGURA 2 - Profissão dos pais dos alunos ingressantes no curso Agronomia do Centro Universitário - FAG 2016.

Em relação ao principal motivo da escolha do curso, pode-se observar na Figura 3 , que $76 \%$ destes alunos possuem identificação com o curso e $19 \%$ acabam tendo uma influência advinda dos pais. Relacionando a Figura 2 com a Figura 3, pode-se observar que a profissão dos pais de certa forma influenciou na decisão da escolha do curso. Ferreira et al, (2015) também mostra que a maioria dos alunos (73\%) de Agronomia da Unioeste no ano de 2012, escolheram o curso por ter certa identificação e interesse.

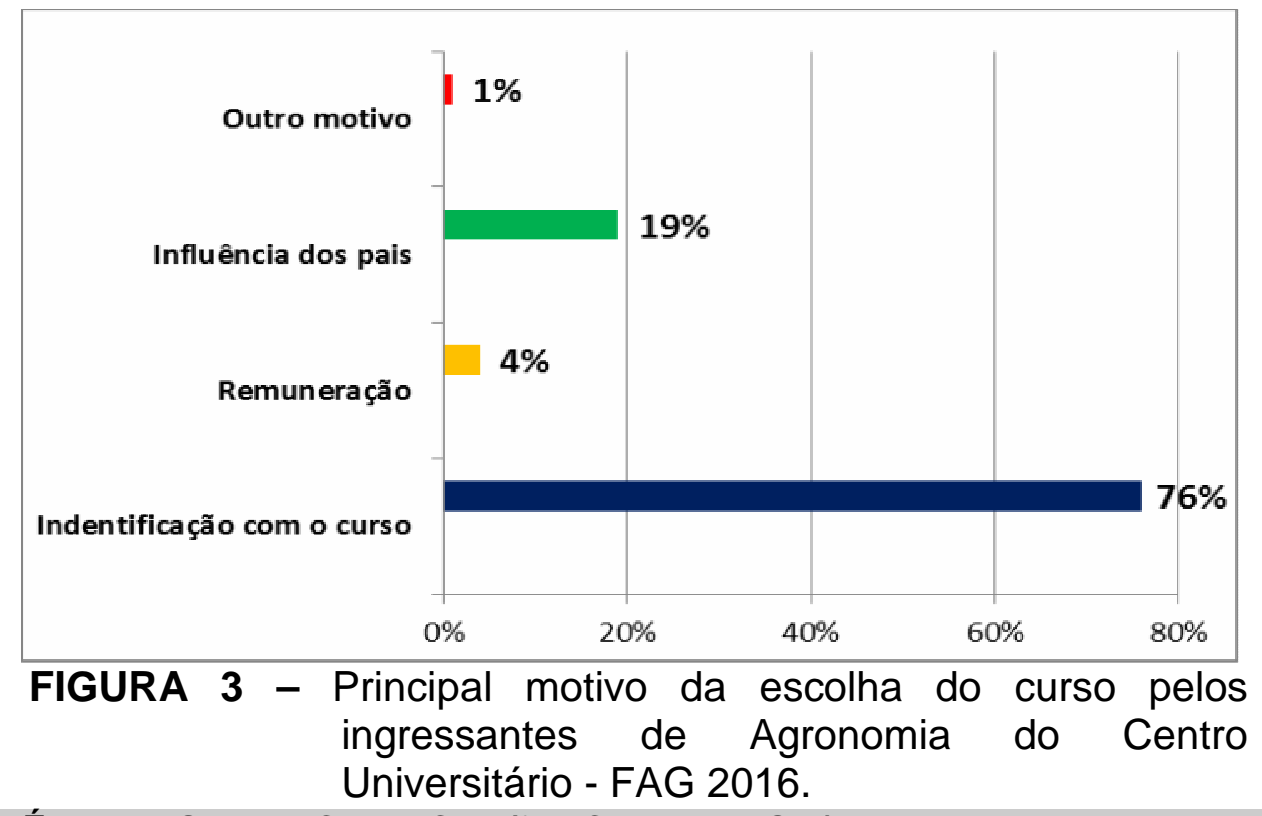

ENCICLOPÉDIA BIOSFERA, Centro Científico Conhecer - Goiânia, v.13 n.24; p.807 
Sobre o trabalho atual dos alunos, $27,7 \%$ estão trabalhando com os pais na propriedade familiar, e $21,6 \%$ já trabalham em algum tipo de comércio, e apenas $15,6 \%$ apenas estuda (Tabela 1 ).

TABELA 1 - Trabalho atual dos ingressantes no curso de Agronomia do Centro Universitário - FAG 2016.

\section{Trabalho dos Acadêmicos Ingressantes}

\begin{tabular}{lcc}
\hline Descrição & Número & $\%$ \\
\hline Agricultura em propriedade familiar & 23 & 27,7 \\
Cooperativa & 11 & 13,2 \\
Revendas & 4 & 4,8 \\
Comércio & 18 & 21,6 \\
Multinacionais & 3 & 3,6 \\
Somente estuda & 13 & 15,6 \\
Outro & 11 & 13,2 \\
\hline TOTAL & 83 & 100 \\
\hline
\end{tabular}

Essas informações vêm a ilustrar a situação atual do país, onde para conseguir manter um estudo de graduação, o acadêmico tem que trabalhar, em sua maioria (84,4\%). Dado observado também por SIMONETTI et al. (2015), onde em seus estudos observaram que $80 \%$ dos estudantes também trabalham para manter o estudo.

Nota-se na Tabela 2, que os alunos almejam para sua carreira trabalhar em Cooperativas $(36 \%)$ e somente $11 \%$ destes pretendem continuar trabalhando na propriedade rural. Tal fator demonstra que cada vez mais os jovens saem do campo em busca de empregos nos centros urbanos. Segundo ARTUZO et al. (2012), $47,46 \%$ dos alunos ingressantes no curso de Agronomia da UFSM, buscam após o término da graduação, se inserir no mercado de trabalho e logo após isso buscam também realizar uma pós-graduação, devido ao mercado exigir cada vez mais qualificações para os serviços.

TABELA 2 - Área que pretendem atuar depois de formados, os ingressantes no curso de Agronomia do Centro Universitário - FAG 2016.

\begin{tabular}{lcc}
\hline \multicolumn{3}{c}{ Pretensão de Atuação Profissional Pós Formado } \\
\hline Descrição & Quantidade & $\%$ \\
\hline Trabalhar na propriedade da família & 9 & 11 \\
Empresa multinacional & 22 & 27 \\
Área de pesquisa & 4 & 5 \\
Professor & 2 & 2 \\
Autônomo & 14 & 17 \\
Cooperativas & 30 & 36 \\
Serviço Público & 1 & 1 \\
Outros & 1 & 1 \\
\hline TOTAL & $\mathbf{8 3}$ & $\mathbf{1 0 0}$
\end{tabular}


Os resultados ainda indicam com ênfase, que $27 \%$ têm a intenção do trabalho em multinacionais; e 17\% têm a intenção empreendedora, de ser autônomo. As multinacionais são destaque pois, segundo DOELLINGER \& CAVALCANTI (1975), são as empresas que localizam-se em setores dinâmicos, concentram maior tecnologia, tem crescimento superior as empresas nacionais, empregam mão-deobra qualificada e pagam salários mais elevados. Por outro lado, também demonstra o quanto é importante que disciplinas ligadas ao empreendedorismo estejam presentes na grade do curso de Agronomia, para que acadêmicos sejam incentivados a este tipo de atuação.

$\mathrm{Na}$ Figura 4, tem-se como principal responsável financeiro dos estudos, os pais, e ao relacionar com a Tabela 1, pode-se inferior que mesmo a grande maioria dos alunos estando inseridos no mercado de trabalho, os pais ainda acabam mantendo esta posição de responsável financeiro pelos estudos. Analisa-se também que $10 \%$ dos alunos acabam obtendo financiamento pelo governo e $2 \%$ possuem outros responsáveis.

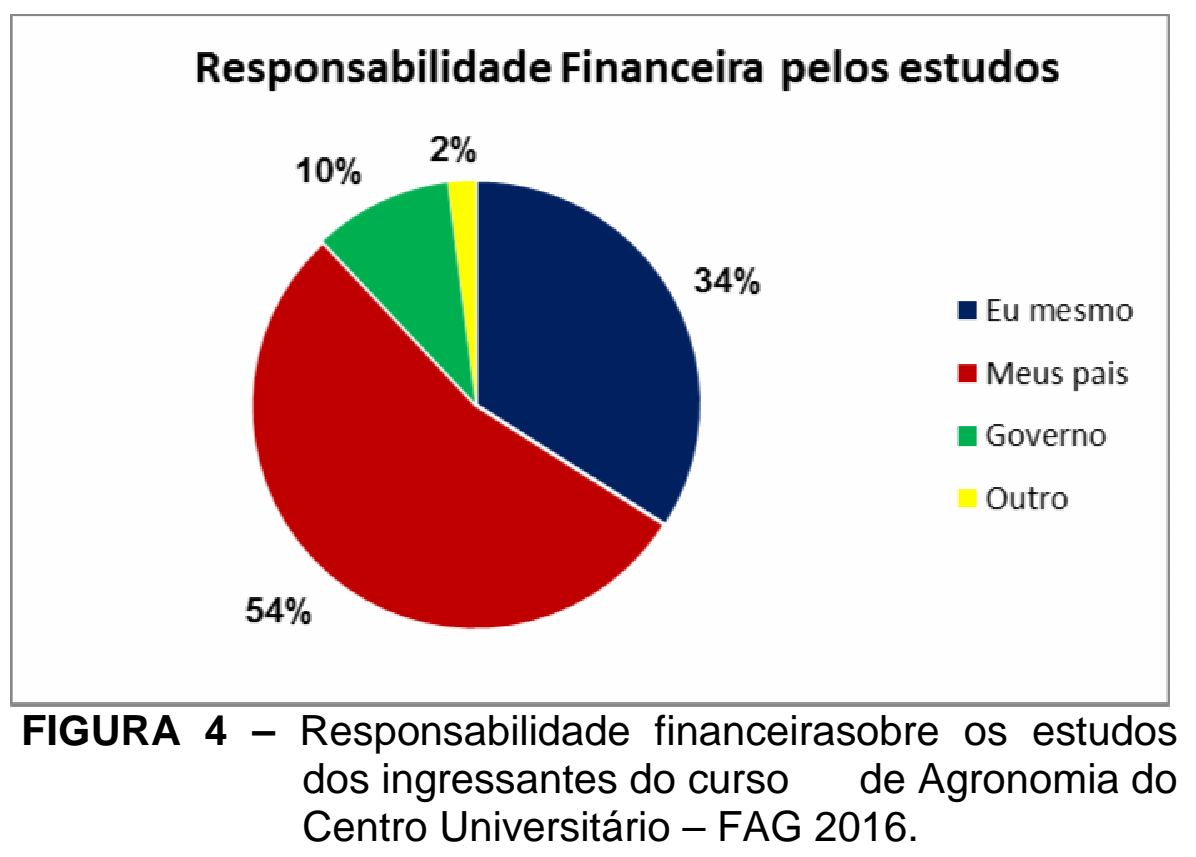

Nota-se que a forma de pagamento mais utilizada é via mensal com $71 \%$, e $10 \%$ tem o financiamento pelo governo (Figura 5). E também 10\% realizam o pagamento anual, sobrando apenas $2 \%$ que utilizam de outra forma de pagamento. Isso nos mostra que o pagamento de forma parcelada (mês a mês) se torna viável aos pais dos alunos. 


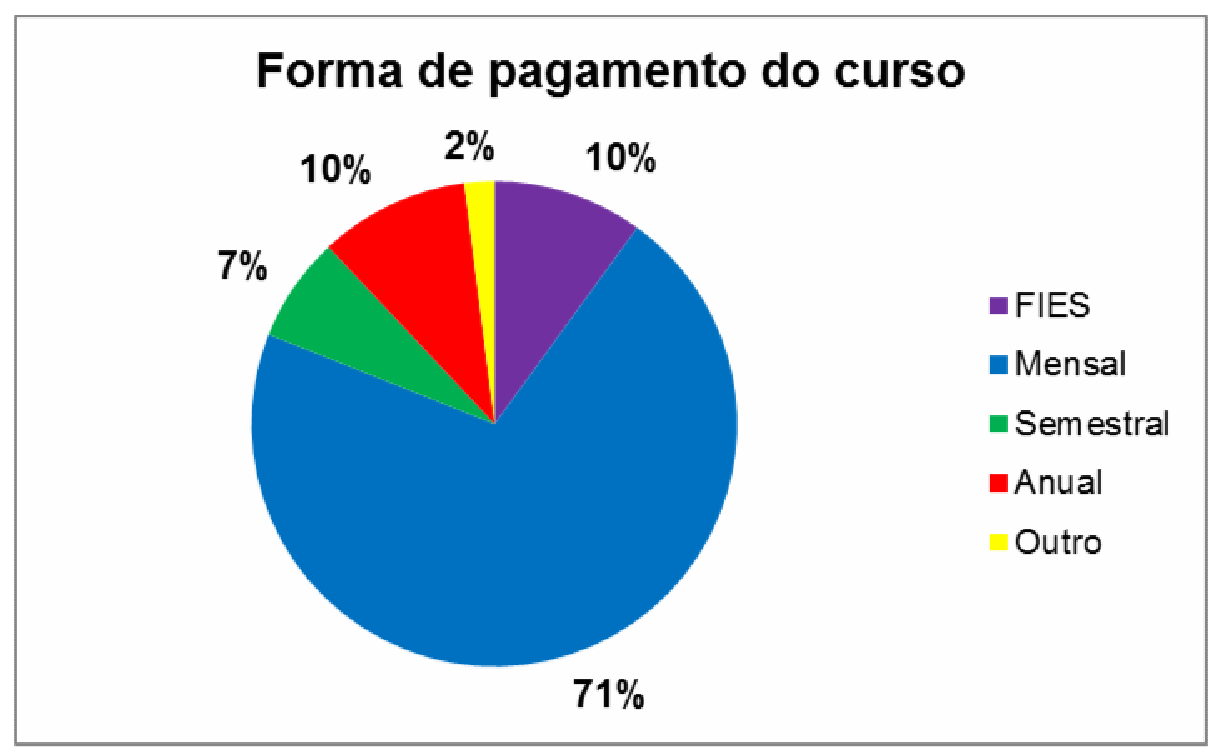

FIGURA 5 - Forma de pagamento do curso de Agronomia do Centro Universitário FAG 2016.

No trabalho realizado no ano de 2015 dos alunos ingressos em Agronomia no Centro Universitário - FAG, SIMONETTI et al., (2015) relataram que $33 \%$ dos alunos possuíam o Financiamento Estudantil do Governo (FIES). A taxa de $10 \%$ observada entre alunos de Cascavel é reflexo direto do corte do governo em relação as bolsas.

E por fim foi analisado o que realmente atraiu os alunos a cursar Agronomia no Centro Universitário - FAG, e os dados indicaram que $52 \%$ destes ingressantes buscam a faculdade pela sua estrutura, o que acaba possibilitando melhores qualidades no aprendizado e uma maior disponibilidade de utilização do Centro para melhor desenvolvimento das aulas, tanto teóricas como práticas.

\section{CONCLUSÃO}

O perfil dos ingressantes no curso de Agronomia do Centro Universitário FAG em 2016 destaca-se pela predominância do gênero masculino, e a maioria dos alunos são de outras cidades, e encontraram em Cascavel o estudo necessário.

Os ingressantes normalmente já encerram o ensino médio e ingressam no ensino supeior, e muitos deles já obtem certo contato e experiência na área da Agronomia. $O$ ensino superior representa uma forma de agregar conhecimento, buscando uma preparação para o mercado de trabalho.

A atração desses ingressantes no Centro Universitario da Faculdade Assis Gurgacz, se deu pela infraestrutura ofertada, onde mostra que mesmo a maioria dos alunos tem o ensino pago pelos pais. Uma pequena parte ainda depende da ajuda ofertada pelo governo para poder cursar um ensino superior.

\section{REFERÊNCIAS}

ARTUZO, F.D.; JANDREY, W.F.; DREBES, L.M.; MONALISA, P. Perfil dos ingressantes do ensino superior do curso de agronomia da UFSM Campus Frederico Westphalen. Enciclopédia Biosfera, v.8, n.15, p. 2528- 2540, 2012.

BORGES, M.N.; AGUIAR NETO, B.G. Diretrizes curriculares para os cursos de Engenharia - Análise comparativa das propostas do ABENGE e do MEC. ABENGE. Revista de Ensino de Engenharia, v.19, n.2, p. 1-7, 2000. 
BRITTO JUNIOR, A. F.; FERES JUNIOR, N. A utilização da técnica da entrevista em trabalhos científicos. Evidência (Araxá), v. 7, n. 7, p. 237-250, 2011.

CAPDEVILLE, G. O Ensino Superior Agrícola no Brasil, Universidade Federal de Viçosa (UFV). Revista brasileira de estudos pedagógicos, v.72, n.172, p.229, 1991.

CARNEIRO, M.J. Ruralidade: novas identidades em construção. Estudos Sociedade e Agricultura, v. 2, n. 11, p. 53-75, 1998. Disponível em: http://r1.ufrj.br/esa/v2/ojs/index.php/esa/article/viewFile/135/131. Acesso em: 9 de setembro de 2016.

CASSOL, A.E.; Agronomia - veja características da profissão, 2014. Disponível em: <http://www.universitario.com.br/noticias/n.php?i=6720>. Acesso em: 11 de setembro de 2016.

CASTRO, E.G. de. Entre ficar ou Sair: uma etnografia da construção social da categoria jovem rural. Rio de Janeiro: PPGEAS - MN - UFRJ, v. 1, n. 8, p. 3 - 427 2005.

DOELLINGER, C.V.; CAVALCANTI, L.C. Empresas Multinacionais na Indústria Brasileira. Rio de Janeiro, IPEA, Relatório de Pesquisa, n. 29, 1975.

ELIAS, M.C.; ROMBALDI, C.V.; MENEGHELLO, G.E. Mais do que 120 anos de aulas, a trajetória da FAEM representa marcas de lição. Revista Brasileira Agrociência, v.9, n.4, p.313-316, 2003.

FAG. Centro Universitário FAG. Disponível em: <http://www.fag.edu.br>. Acesso em: 9 de setembro de 2016.

FERREIRA, D.S.; EGEWARTH, V.A.; PASTÓRIO, M.A.; YASSUE, R.M.; ACHRE, D.; SILVA, N.L.S. Perfil sócio econômico e cultural de ingressos no curso de agronomia da unioete no ano de 2012. Journal of Agronomic Sciences, v.4, n.1, p.127-138, 2015.

GIL, A. C. Métodos e técnicas em pesquisa social. São Paulo: Atlas, 1999.

INEP. Censos Escolares da Educação Superior 2015. Disponível em: <http://portal.inep.gov.br>. Acesso em: 16 de outubro de 2016.

KAGEYAMA, A. Os rurais e os agrícolas de São Paulo no Censo de 2000. Caderno de Ciências e Tecnologia, v.20, n.3, p.413-451, 2003.

PAIVA, G. S. Avaliação do desempenho dos estudantes da educação superior: a questão da eqüidade e obrigatoriedade no Provão e Enade. Rio de Janeiro, RJ, 2008.

RONCA, A. C. C.; RAMOS, M. N. (coord). Da CONAE ao PNE 2011 - 2020: Contribuições do Conselho Nacional de Educação. Moderna. São Paulo, 2010. $281 \mathrm{p}$. 
SAMPAIO, H. "O setor privado de ensino superior no Brasil: continuidades e transformações." Revista Ensino Superior Unicamp. p. 28-43, 2011. Disponível em:https://www.revistaensinosuperior.gr.unicamp.br/edicoes/ed04_outubro2011/05_ ARTIGO_PRINCIPAL.pdf Acesso em: 19 de outubro de 2016.

SICSÚ, J.; CASTELAR, A. Sociedade e economia: Estratégias de crescimento e desenvolvimento. Brasília: IPEA, 252 p., 2009.

SIMONETTI, A.P.M.; CORTI, G.; BIANCHINI, E.; SCOPEL, E.; WITT, T.V.; FELDHAUS, W. Caracterização do perfil dos alunos ingressantes 2015 no Curso de Agronomia da Faculdade Assis Gurgacz - Cascavel - PR. Revista Cultivando o Saber, v. 8, n.4, p. 357-372, 2015.

STROPASSOLAS, V.L. O mundo rural no horizonte dos jovens. Florianópolis: UFSC, v. 1, n. 1, 346p. 2006. 